\title{
Energy Metrics for Water Distribution System Assessment
}

\author{
Rebecca M. Dziedzic and Bryan W. Karney
}

\begin{abstract}
Water and energy, more than key inputs to most human activities and important ecosystem services, share an important nexus. By analyzing the connections between these resources, more holistic, and sustainable solutions can be achieved. How energy is transformed and displaced throughout a water distribution network is an indicator of system characteristics. The present study proposes energy related sustainability metrics for water distribution systems: energy supplied, lost, dissipated, potential, and delivered. These respectively correspond to energy provided to the system, lost through leaks, used to overcome friction, used to overcome differences in elevation, and delivered to the user in the form of pressure and demand. The metrics are based on EPANET hydraulic modeling outputs. Aggregate results of the system are indicators of capacity, efficiency, and costs. When mapped, the metrics provide a geographical snapshot of the system, and allow for better identification of pressure districts, or even specific mains, pumps, and tanks, where dissipations are high or energy delivered is in excess, and changes are most beneficial. Through this deeper understanding of the cost generating and revenue producing parts of the system, more effective stewardship can be achieved; rate structures, and even standards can begin to be rethought.
\end{abstract}

Keywords: water distribution, EPANET, modeling, water energy nexus.

\section{Introduction}

Water and energy, more so than key inputs to most human activities and important ecosystem services, share an important nexus. By analyzing the connections between these two resources, more holistic, and sustainable, solutions can be achieved. Electricity consumption is responsible for a significant part of greenhouse gas emissions and for the costs of water distribution. Furthermore, since energy is proportional to the product of pressure and flow, it integrates these two key parameters of the system. Thus, how energy is transformed and displaced throughout a network is an indicator of other system characteristics.

The present study proposes energy-related sustainability metrics for water distribution systems: energy supplied, lost, dissipated, potential, and delivered. These correspond, respectively, to energy provided to the system, lost through leaks, used to overcome friction, used to overcome differences in elevation and delivered to the user in the form of pressure, and demanded. The metrics are based on EPANET hydraulic modeling outputs, flow and head. Aggregate results of the system are indicators of capacity, efficiency and costs. When mapped, the metrics provide a geographical snapshot of the system, and allow for better identification of pressure districts, or even specific mains, pumps and tanks, where dissipations are high or energy delivered is excessive, and changes are most beneficial. Through this deeper understanding of the cost generating and revenue producing parts of the system, more effective stewardship can be achieved; rate structures, and even standards, can be rethought.

\section{Water Energy Nexus}

Water and energy are intertwined in natural and anthropogenic processes. The core of what has been called the water-energy nexus today is that water is used to generate energy, and energy is used to pump, treat and heat water (Maas 2010). Water scarcity, greenhouse gas emissions from fossil fuel based energy generation, and costs for both resources, all create pressure on either side of this nexus. The integration of water and energy can thus create synergies and allow for more holistic and sustainable solutions.

As enthusiastically phrased by Hussey and Pittock (2012), systems thinking and policy integration is the holy grail in this context. According to those authors, three major barriers which prevent greater integration between the sectors are: data (missing or disorganized), existing policies and frameworks (fragmented, inconsistent or lacking review) and cultural inertia and path dependency (silo mentality). In order to overcome these obstacles, questions must be asked of policy makers, managers, engineers, researchers and the users, in order to better understand and address water-energy issues.

Dziedzic, R. and B. Karney. 2014. "Energy Metrics for Water Distribution System Assessment." Journal of Water Management Modeling C368. doi: 10.14796/JWMM.C368.

() CHI 2014 www.chijournal.org ISSN: 2292-6062 


\section{Water Distribution}

Water supply and distribution systems are designed to deliver water, and in many industrial cities they perform this task very well. These systems deliver large quantities of water for many human purposes: to meet residential and household demand and for a wide range of industrial and commercial purposes; for cooling and cleaning and increasing human comfort; to further the growth of various plants and animals; for aesthetic reasons; to facilitate or limit the rate of chemical reactions; and to fight fires. The water that is delivered must not only arrive in the quantity desired, and whenever it is desired, but also with a suitable chemical purity, at an economically practical price and at a suitable pressure.

These water-connected roles can be taken for granted. Urban dwellers in general have come to expect that water delivery tasks will be carried out quietly, efficiently, reliably, cheaply and virtually effortlessly. According to The Nature Conservancy (2011), 77\% of Americans, excluding those that receive well water, cannot accurately identify the natural source of water used in their homes. Nevertheless, given the historic need for moving water and building distribution systems, this technology is expected to be well known, principles to be clear, systems in place and the appropriate people hired to perform the wide range of management services associated with a range of water delivery related activities.

The roles that were readily assumed in the past to be easily met are becoming potentially more costly than imagined, more vulnerable, and more challenging. Globally, cities and human populations have grown, human expectations for clean water have tended to increase, and the overall material wealth of society has expanded. This has meant that water demand globally has grown. However, overall, the most available water and associated energy demands needed to obtain, treat and distribute this water have grown too, while infrastructure has aged.

According to EPRI (2002), in the United States $\sim 4 \%$ of electricity use goes towards moving (80\%) and treating water and wastewater. Furthermore, $\sim 80 \%$ of municipal water processing and distribution costs are for electricity. Regardless of size, the predominant use of electricity is for pumping treated water in the distribution system, representing $80 \%$ to $85 \%$ of the total electricity consumption for surface water treatment. If groundwater is the source of supply, energy requirements increase $~ 30 \%$ on a unit basis, compared to surface water (EPRI 2002).

Rothausen and Conway (2011) believe the current low recognition of the water-energy nexus is reflected in the lack of peer reviewed publication on the subject, specifically in addressing energy use and consequent greenhouse gas emissions. However, life cycle analyses of water infrastructure (Stokes and Horvath 2011) have already indicated that the operational phase of water is responsible for most of the environmental impacts, $67 \%$ of greenhouse gas (GHG) emissions. And these are significantly due to energy use, which contributes to $50 \%$ of total GHG emissions.
The long life cycles of water mains, equipment and appurtenances explain the prominence of the impacts during the operations phase. It also means that many systems that were built in the latter part of the nineteenth century and throughout the twentieth century, when urbanization became more widespread and intense, have never experienced the need for large scale replacement. The recognition of this need means a growing financial stress on communities, adding unknown costs to the more apparent above-ground expenses required to meet standards and other needs. Aging infrastructure is more subject to breaks and other failures that can threaten public health and safety, as well as wastewater and energy. Repair is also costly and may disrupt business and residences. Nevertheless, not undertaking frequent maintenance and replacement is generally worse over the long term (AWWA 2012).

Increasingly, the easiest water and energy sources, have already been harvested, tapped or otherwise exploited. Water shortages now exist in many parts of the world such that a great deal of the world must learn to cope with intermittent and unreliable water supply systems, systems that no longer meet their delivery requirements continuously. Thus, new strategies need to be used in the quest to find less resource intensive alternatives to water supply. But, all these supply systems, whether in their best state or their most physically degraded, do not simply deliver water, they deliver water under pressure-energized water.

\section{Energy as a Metric for Water Distribu- tion System Sustainability}

This study seeks to develop water distribution sustainability metrics that can easily be calculated and be used to inform decision making. Energy use is not only an important cost and a GHG generating part of the water distribution system; the way in which energy is used and transformed throughout the system is an indicator of performance and sustainability. According to Kumar and Karney (2012), energy is one of the most practical abstractions. In addition to being an economic commodity, it is a conceptual framework that can be used to gauge the usefulness, viability and character of many other things. Similar to currency, energy is conserved and its flows through the system and changes in form can be accounted for. These attributes show energy has the potential to be used as a key measure of the value of a traded commodity.

Specifically in water distribution, energy also integrates the two key parameters of the system: pressure and flow. These are standardized and thus controlled by utilities, yet at varying levels of geography and time steps. They can be further modeled with readily available software, such as EPANET, and the results of modeling can be used to calculate detailed metrics. Energy, a function of power, can be determined by the product of head, flow, and a constant (Equation 1).

$$
E=\int_{0}^{t} P d t=\int_{0}^{t}(\gamma H Q) d t
$$


where:

$$
\begin{aligned}
P & =\operatorname{power}(\mathrm{W}), \\
\gamma & =\operatorname{specific} \text { weight }\left(\mathrm{N} / \mathrm{m}^{3}\right), \\
H & =\operatorname{head}(\mathrm{m}), \text { and } \\
Q & =\text { flow }\left(\mathrm{m}^{3} / \mathrm{s}\right) .
\end{aligned}
$$

The shaded areas in Figure 1, of head versus flow, are therefore proportional to energy consumption. The minimum head requirements are a sum of elevation differences, a constant, which must invariably be met by the system, and minimum pressure requirements. The curve is created by the increase in head loss with higher demands. The energy supplied to the system does, however, generally surpass requirements, due to wasteful consumption, leaks, excessive pressures and inadequate operational standards. Reducing energy consumption means moving the point of operation closer to the origin. Head and flow should be optimized together for better results. Since these parameters are inherently related, and condition the system, their integration can also create important synergies.

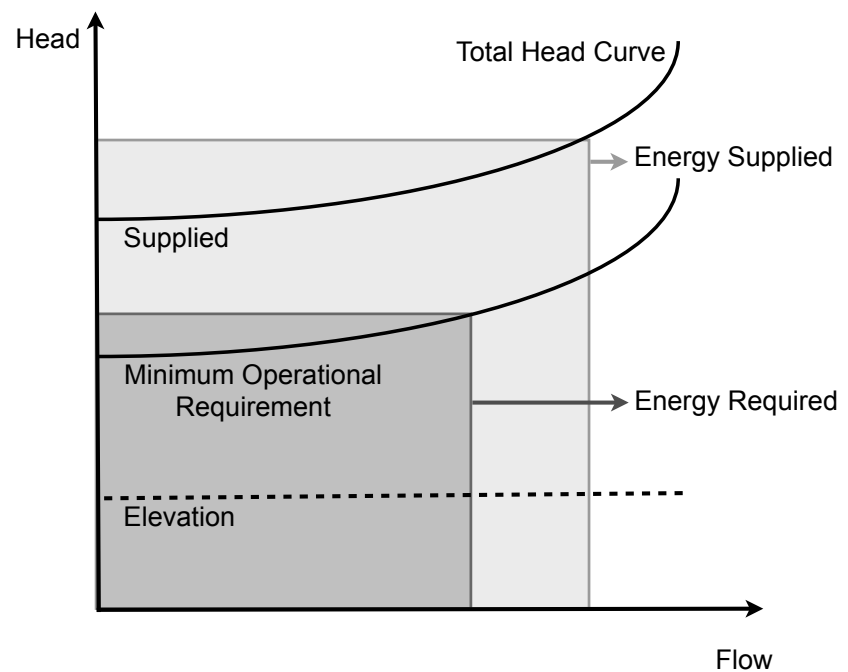

Figure 1 Schematic representation of system curves and corresponding energy consumption for minimum requirements and supplied head and flow.

\section{Proposed Metrics}

Energy is required for three main applications in the distribution system: to overcome elevation differences, to compensate for losses, and dissipation. Energy is supplied to the water at reservoirs or in tanks as potential energy, or through pumps as kinetic energy. Part of this mechanical energy, however, is irreversibly converted to thermal energy throughout the system, less valuable in moving the fluid, in a process of dissipation. Energy, together with water, is also lost through leaks. Thus, only a portion of the energy that enters the distribution system is delivered to the consumer. This inefficiency depends on characteristics of the infrastructure, the operation, and the user.
The amount of energy in water distribution, and its different forms, can be estimated with hydraulic simulators that are readily available, such as EPANET. By developing sustainability metrics based on model outputs, a more detailed analysis, with different scenarios and small time steps, can be completed. According to Sahely and Kennedy (2007) system aggregation, such as in life cycle assessments, has drawbacks in performance assessment of the water distribution system; the use of a network model can help to target pipe breaks, leaks, associated water losses, energy impacts and demand management.

Modeling results are usually presented in time steps. Thus, an average energy flow may be considered over the given period, $t$, as indicated by Equation 2, where the overbar indicates a time average.

$$
E=\bar{P} \cdot t
$$

Since energy is conserved, inputs equal outputs, and energy supplied can be described by the sum of its different forms as it passes through and leaves the system, as indicated in Equation 3.

$$
\sum E_{\text {supplied }}=\sum E_{\text {dissipated }}+\sum E_{\text {lost }}+\sum E_{\text {delivered }}
$$

where:

$E_{\text {dissipated }}=$ energy dissipated in pipes, pumps and valves due to friction and inefficiency (Wh),

$E_{\text {lost }}=$ energy lost due to leakage of pressurized water (Wh), and

$E_{\text {delivered }}=$ energy delivered in the form of pressure, including requirements and excess energy (Wh).

Each of these forms of energy, related to changes in the energy grade line, is represented in Figure 2.

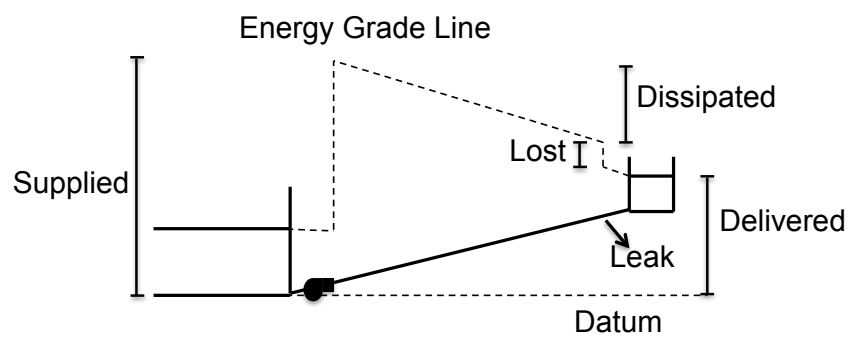

Figure 2 Schematic representation of the different forms of energy in a water distribution system with a single reservoir, pump, pipe and tank.

Energy lost is proportional to the difference in head between the inside and the outside of the pipe, $\Delta H_{\text {leak }}$ (Equation 4), approximately the pressure of the flow. Usually, however, detailed leakage information is not included in the models of municipalities. Locating unreported bursts is a cumbersome task, and requires expensive specialized equipment, which makes it economically and technologically infeasible (Tabesh et al. 2009). Instead, leakage is modeled as equally distributed throughout the system or by district meter area (Thornton 2002, chap. 7). This 
means $E_{\text {lost }}$ is aggregated and approximated as a percentage of $E_{\text {delivered }}$.

$$
E_{\text {lost }}=\gamma \cdot \Delta H \cdot Q_{\text {leak }} \cdot t
$$

A leak affects the flow upstream and downstream. The excess flow, necessary to compensate leakage, increases head loss, and consequently energy requirements. Pressures simulated in the model may be higher or lower than in reality, depending on how the network is calibrated and leaks are allocated. The amount of error will be inversely proportional to the size of the metered areas in the network, since in smaller areas localized leaks are subject to less averaging.

Energy dissipated is calculated according to Equation 5.

$$
E_{\text {dissipated }}=\gamma \cdot H_{\text {loss }} \cdot Q \cdot t
$$

where:

$$
\begin{aligned}
H_{\text {loss }}= & \text { head loss }(\mathrm{m}), \text { which includes minor and friction } \\
& \text { losses. }
\end{aligned}
$$

Head loss across pipes is based on the unit head loss calculated in EPANET. Energy dissipated in pumps occurs due to friction and inefficiency, which can be calculated based on the total head supplied and net head gain provided by EPANET.

Head loss, and thus energy dissipated, is directly proportional to pipe roughness and varies inversely with diameter. Friction may not be the primary cause of main breaks, yet greater roughness and smaller sections caused by tuberculation also increase the probability of failure. Thus this metric can be used as an indicator of pipe susceptibility to bursts, and be further compared to historic data for more robust analyses.

Analogous to energy dissipated, energy delivered and energy supplied are given by Equations 6 and 7. Energy is delivered when demand is positive and supplied when negative.

$$
\begin{aligned}
& E_{\text {delivered }}=\gamma \cdot H_{\text {node }} \cdot Q_{\text {delivered }} \cdot t \\
& E_{\text {supplied }}=\gamma \cdot H_{\text {node }} \cdot Q_{\text {supplied }} \cdot t
\end{aligned}
$$

where:

$$
\begin{array}{r}
H_{\text {node }}=\begin{array}{l}
\text { head delivered at or supplied by the node, } \\
\text { depending on the direction of flow (junctions, } \\
\text { tanks and reservoirs may have dual behaviours). }
\end{array} \\
\text { Energy supplied is an indicator of the capacity of the sys- }
\end{array}
$$
tem. Water, as it enters the distribution system, even before being pumped, contains energy imparted from the accumulation in reservoirs. Pumps then meet the energy requirements that could not be fulfilled by the mere differences in elevation within the system. Although the supply at junctions is not linked to a source of water, a negative demand can be used in the network to model a groundwater pumping well or to enforce a specific schedule of inflow. At tanks, even though energy is not truly supplied, only stored, the differences between supply and delivery reflect the changes in storage. Note that the terms reservoirs and tanks are applied in agreement with their definitions in EPANET (Rossman 2000). Reservoirs are assumed to be nodes that represent an infinite external source or sink of water to the network. Tanks are nodes with storage capacity, the volume of which can vary with time during a simulation.

Energy delivered, proportional to total head at the nodes, encompasses pressure and elevation. Pressure delivered, however, rarely equals requirements. Consumers demand different pressures, especially in the industrial sector, and can be scattered around the network. This means there is generally a surplus of energy in certain areas and perhaps a deficit in others. Excess pressure can cause higher burst rates, increased leakage, and costs, all effects which pressure management seeks to curtail (Gomes et al. 2011).

Mapping of these metrics provides a geographical snapshot of the water distribution system operation and facilitates reallocation studies. Areas with high energy requirements, and therefore high associated operational costs, can easily be identified. Pipes with excessive dissipation can also be highlighted for increased care and further exploration, given their proneness to bursts. With regards to energy delivered, attention should be paid to the area supplied by each node. If future scenarios are modeled, for instance, yet future trunks are not included and only nodal demand is increased, results might appear artificially high.

Overall, the ability to identify hot spots of energy use, and compare scenarios according to simple metrics, facilitates the assessment of sustainability of the system. The utility, provider of the service of water distribution, can better understand what the user is receiving, besides water, and what this entails operationally. Therefore cost and revenue can be allocated more wisely, and the question of prioritization-what and where utilities should focus on-can be answered. All of this contributes to more effective stewardship and should be associated with further research and other initiatives for continuous improvement.

\section{Energy Metrics of a Hypothetical System}

The proposed energy metrics were calculated for a hypothetical water distribution system modeled in EPANET. The system, shown in Figure 3, has nine junctions, with distinct demands, eleven pipes of different lengths and diameters, one reservoir, pump, and tank. Details of the topology of the network are described in Table 1. The pump, which has a constant efficiency of $75 \%$, is cycled according to tank level. It is opened if tank level is $<35 \mathrm{~m}$, and closed if $>45 \mathrm{~m}$.

A $24 \mathrm{~h}$ simulation was completed with demands varying throughout the day. Maximum demand is at $6 \mathrm{~h}$ and minimum at $18 \mathrm{~h}$. This is different than expected for real water distribution systems where there are usually two peaks, in the morning and afternoon, and minimum demand occurs at night. In the modeled network, average head initially increases with demand (Figure 4) yet changes behaviour and varies inversely with demand after $11 \mathrm{~h}$. This is a reflection of the operation of the system, the pump and tank control. Average head increases as the tank is being filled (level increasing from $35 \mathrm{~m}$ to $45 \mathrm{~m}$ ), and the pump is open. It decreases as the tank is emptied (level decreasing from $45 \mathrm{~m}$ to 
$35 \mathrm{~m}$ ), the pump is closed, and the reservoir is thus not supplying water.

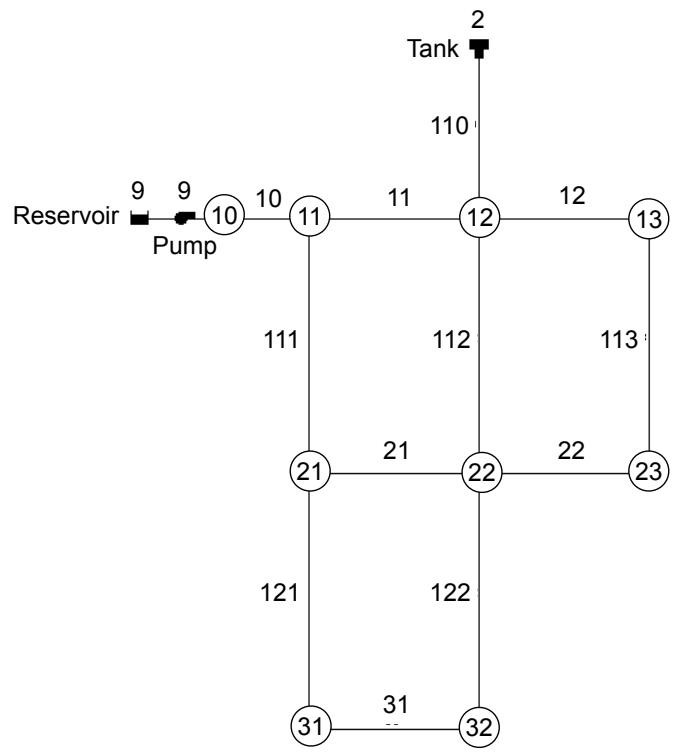

Figure 3 Network of the hypothetical system.

Table 1 Topology of the hypothetical system.

\begin{tabular}{cccccc}
\hline Pipes & Length $(\mathrm{m})$ & $\mathrm{D}(\mathrm{mm})$ & Nodes & Elev. $(\mathrm{m})$ & Initial Demand $(\mathrm{L} / \mathrm{s})$ \\
\hline P 10 & 3200 & 450 & $\mathrm{~J} 10$ & 215 & 0 \\
P11 & 1600 & 350 & $\mathrm{~J} 11$ & 215 & 10 \\
P12 & 1600 & 250 & $\mathrm{~J} 12$ & 210 & 10 \\
P21 & 1600 & 250 & $\mathrm{~J} 13$ & 205 & 5 \\
P22 & 1600 & 200 & $\mathrm{~J} 21$ & 210 & 10 \\
P31 & 1600 & 150 & $\mathrm{~J} 22$ & 205 & 15 \\
P110 & 60 & 450 & $\mathrm{~J} 23$ & 200 & 10 \\
P111 & 1600 & 250 & $\mathrm{~J} 31$ & 210 & 5 \\
P112 & 1600 & 300 & $\mathrm{~J} 32$ & 215 & 5 \\
P113 & 1600 & 200 & Res 9 & 250 & \\
P121 & 1600 & 200 & Tank2 & 260 & \\
P122 & 1600 & 150 & & & \\
\hline
\end{tabular}

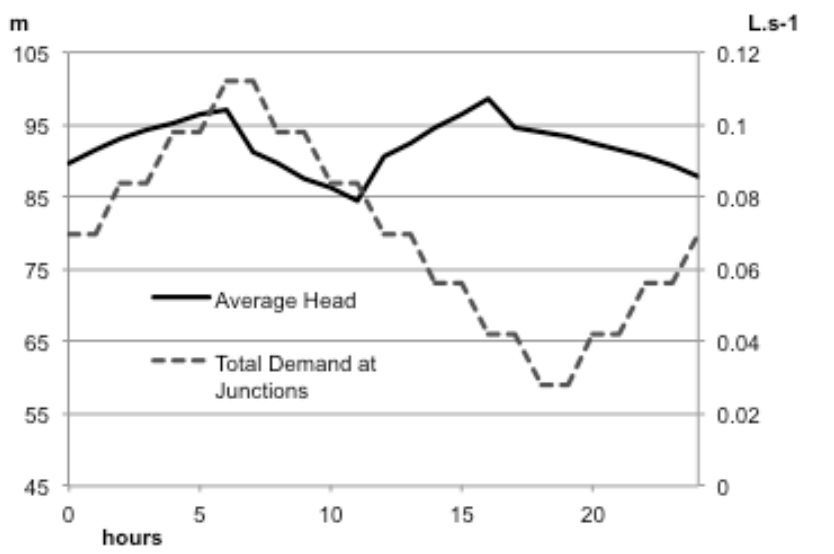

Figure 4 Average head (pressure and kinetic) and total demand at junctions per hour.
Energy is therefore supplied either by reservoir and pump or solely by the tank, depending on the tank level. However, if the datum is set at the level of the reservoir, which better represents the energy requirements of the system, energy supplied at the reservoir is null (Figure 5). Furthermore, peaks in energy supplied correspond to periods of tank filling. These correlations become less obvious in more complex systems, where various reservoirs, pumps and tanks exist. Modeling then becomes an instrumental tool in better analyzing and improving these systems.

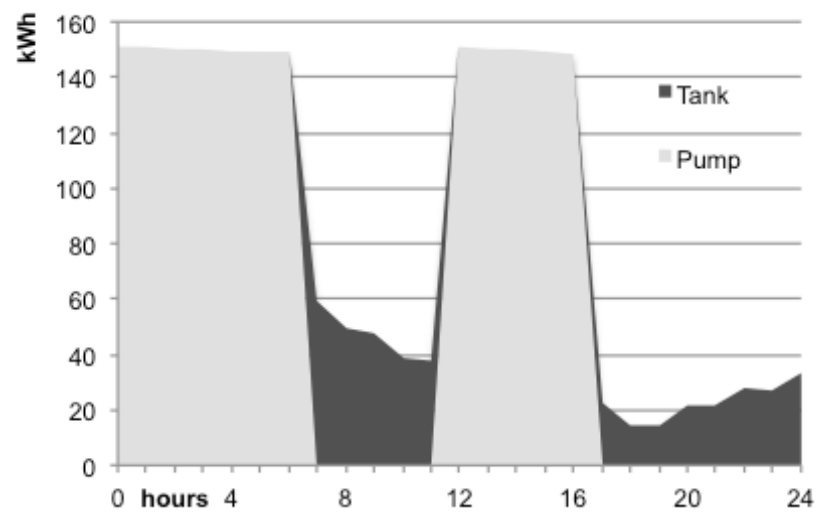

Figure 5 Energy supplied per hour by tank, reservoir and pump.

Since leaks were not included in this model, energy supplied equals the sum of energy dissipated and delivered (Figure 6). Dissipation is minimal when tanks are supplying water. It significantly increases when pumps are being used, due to their higher dissipation rates and larger flows. Overall, energy dissipated represents $38 \%$ of energy supplied. In real networks, with longer pipe lengths, and probably higher velocities (average velocity in the model is $\sim 0.4 \mathrm{~m} / \mathrm{s}$ ), this value might increase. The model has $\sim 19 \mathrm{~km}$ pipe, which is dwarfed by the $\sim 6000 \mathrm{~km}$ of water mains in Toronto. Also, because of leakage, energy delivered to the user would be reduced as well.

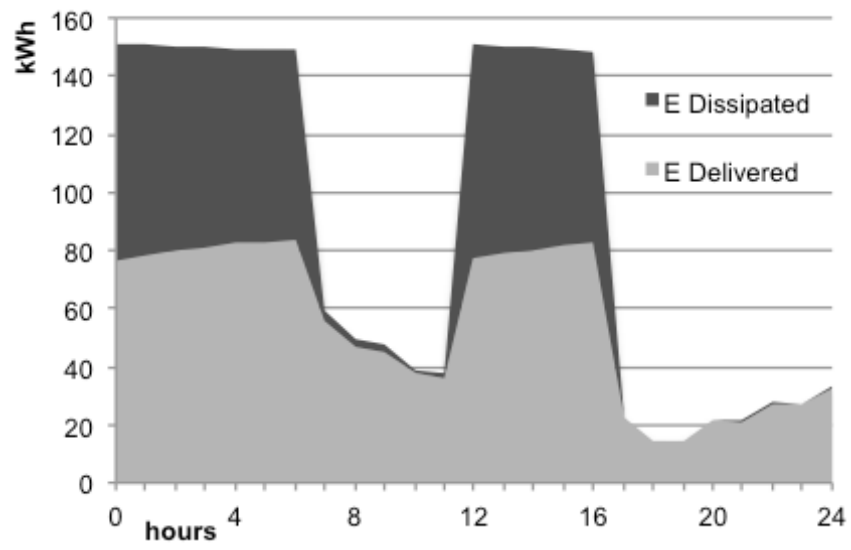

Figure 6 Total energy supplied per hour, separated into energies dissipated and delivered. 
Mapping these metrics allows for a deeper analysis of the system as it facilitates the identification of specific parts of the network which require attention or improvement. In Figure 7 the energy metrics are mapped for two scenarios: maximum demand (a) and minimum demand (b). The shades of grey of the nodes indicate whether energy is being supplied or delivered, and their size is proportional to the amount of energy entering or leaving the system at that point. For the pipes, the shades of grey identify the extent of energy dissipated.

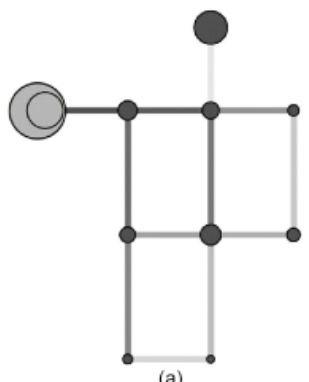

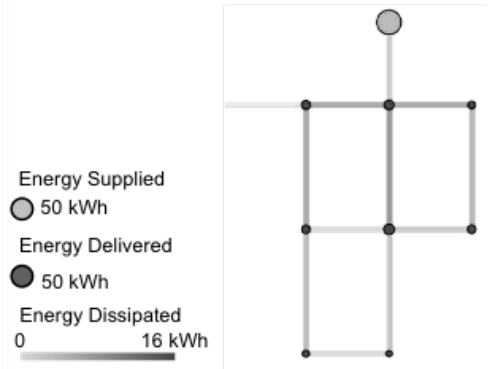

(b)
Figure 7 Energy metrics mapped for the hypothetical system, at (a) peak demand, $6 \mathrm{~h}$ and (b) minimum demand, $18 \mathrm{~h}$.

During maximum demand it can be observed that the reservoir and pump are the only suppliers of energy, whereas during minimum demand they are not being used and the tank has become a source. Especially at peak demand, energy dissipated, even though a function of many variables, can easily be seen to be highest where water leaves the source. Closer to the supply of water, flows are larger and pressures are higher since fewer delivery points have been reached and less pipe length has been traversed. During minimum demand, although only the tank supplies water, total energy dissipated is not highest at the subsequent pipe (110) because of its smaller length. Since pressures vary less throughout the network than does flow, variations in energy delivered can be explained by differences in demand. Junction 22, at the center of the network, has the highest demand and energy delivered.

The high dissipation at pipe 112, and high demand at junction 22, subsequent to it, create a setting for potential leakage. The hypothetical system, results of which have been presented thus far, was modified to include a leak in the middle of pipe 112. This was defined as an emitter in EPANET, with a pressure exponent of 1 , as suggested by Lambert (2000). The discharge coefficient was set to 0.05 , and the base demand at junction 22 reduced from $15 \mathrm{~m}^{3} / \mathrm{s}$ to $10 \mathrm{~m}^{3} / \mathrm{s}$, in order to keep demands similar to those in the no leakage scenario.

With these modifications, energy delivered represents a smaller portion of energy supplied, 59\%. Energy dissipated remains approximately $38 \%$, and energy lost equals the remaining $4 \%$. The hourly variation of the energy metrics is not significantly altered; Figure 8 is very similar to Figure 6 . This is because energy lost remains fairly constant throughout the day. However, due to the fluctuation in the other metrics, the percentage of losses varies markedly. It is lowest at 6 h, $4 \%$, when demands are high and the reservoir is supplying energy, and highest at $18 \mathrm{~h}, 16 \%$, when pressures are high, demands are low, and the tank is supplying. The percentage of water lost varies more, between $1 \%$ and $16 \%$.

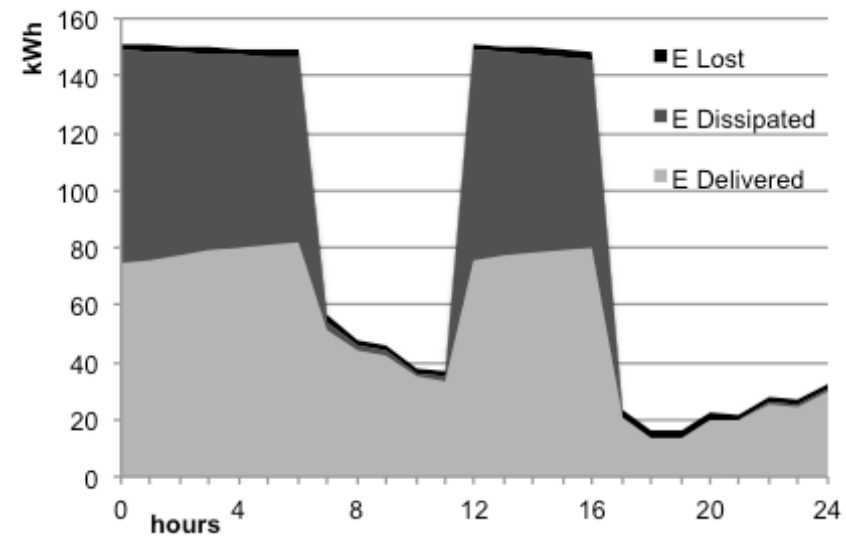

Figure 8 Total energy supplied per hour in the hypothetical system with leakage, separated into energies lost, dissipated and delivered.

By mapping the energy metrics of this modified system, Figure 9, it is apparent that energy delivered remains relatively unchanged, except for junction 22, where demand was reduced. Dissipation is decreased in the portion of pipe 112 subsequent to the leak. Values, however, cannot be directly compared between the two scenarios because demands do not always correspond.

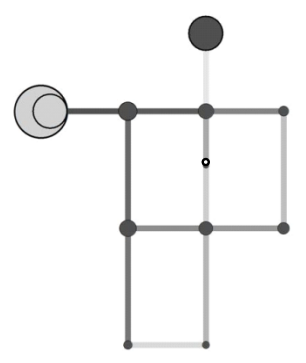

(a)

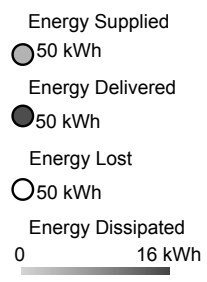

$16 \mathrm{kWh}$
Figure 9 Energy metrics mapped for the hypothetical system with leakage, at (a) peak demand, $6 \mathrm{~h}$ and (b) minimum demand, $18 \mathrm{~h}$.

In a real network, attention would have to be given to those pipes with the highest dissipation and greater probability of cracking and bursting. The variation in energy supplied by pumps would have to be analyzed together with electricity prices and greenhouse gas emissions, with the objective of increasing the sustainability of the system. The cause for the differences in demand would be further investigated, whether brought upon by network skeletonization, actual variations in population density, or characteristics of the community. Also the source of the water, surface or groundwater, local or imported, can be an indicator of 
system priorities, water conservation, energy efficiency, or cost reduction.

\section{Rethinking the System Energy Require- ments}

In order to decrease energy consumption in the system, and related costs, two main strategies exist: to reduce pressure, and to reduce flow. These can be achieved, to different degrees, through varying approaches, since they are influenced by operations, maintenance, standards, utility and government programs, as well as user requirements, needs, and values. The effects of these system interactions are explored hereafter. For each system, further analysis is needed for identifying the best course of action, according to local characteristics: major issues, motivations and restraints.

\subsection{Pressure Reduction: Beyond Pressure Man- agement}

Without pressure, water would only be nominally present in the distribution system, found in the delivery pipe perhaps, but unable to complete the task it was intended to perform. Furthermore, in this case, ambient water might ingress affecting the quality of the water being distributed. If that water is available under pressure, and thus at a pressure level beyond the local elevation, any local path that is established to the atmosphere allows for flow of water moving from pipe to shower, to dishwasher, garden hose or fire hydrant. Thus it is this energized water, not only the water itself, that does the real work at the delivery end of the supply system.

Attention must be drawn to the fact that pressure itself is potentially lethal and certainly hazardous. Indeed, if the delivery pressures are too high, pipes tend to break, sometimes violently; valves fail prematurely, requiring costly replacements; devices underperform, and so increase expenses. Negative pressures can be damaging to existing infrastructure, possibly resulting in pipeline collapses, and removing one of the key barriers that prevent water contamination. Although pressure is a necessity, it must be carefully managed, since its excess or deficit can cause a nuisance or a hazard.

Equipment in industrial buildings and appliances in residential dwellings are designed for specific pressure ranges. Customers are also accustomed to specific water pressures coming from their faucets and shower heads. The failure to meet operational standards, even before affecting user safety, can thus cause customer dissatisfaction and complaints. This does not mean, however, that these pressures, above safety requirements, are essential. Better integration between supply and demand side decisions could prompt more sustainable water and energy use.

System design is a challenging task. There are countless decisions to make: the pipes and their sizes, the pumps and their placements, the reservoirs, and pressure district boundaries, the material choices and economic staging, the water quality changes and their management. In order to simplify this task, and set reasonable operating conditions so that sufficient pressure is supplied (but not so much as to be dangerous), various local standards have been set.

The goal of these standards is to meet reasonable expectations so that the designers and the users of the supply system can have compatible expectations and requirements. Despite fluctuating demand, adequate pressure must be maintained in the distribution network to ensure acceptable water quality and delivery rates. Standards simplify the task of designing for the unknown, accounting for uncertainties and risks. However, specificity is relinquished as potential problems are generalized. Overdesign, generally attributed to safety requirements, then becomes an issue.

Pressure management, a prominent current approach for controlling pressures through the installation of valves in the distribution system, has various advantages: decrease in burst frequency, improved system performance and reliability, and extended asset life. From the perspective of energy consumption, additional benefits might be gained with the extension of pressure management to include the reduction of energy supplied. Even within the AWWA recommendations (Deb et al. 1995) of a minimum pressure goal range of $21 \mathrm{~m}$ to $28 \mathrm{~m}$ and a maximum pressure goal range of $56 \mathrm{~m}$ to $70 \mathrm{~m}$, space for improvement might be found. Alterations to operational standards will undoubtedly affect the manner in which the system functions. Depending on the design of the system and its current operations, the reduction of pressure may cause more pump cycling (starting and stopping).

\subsection{Water Conservation: Planning More Efficient Consumption}

A decrease in pressure obviously reduces costs. Water conservation and reduction in expenses, however, are sometimes deemed opposing objectives. This misconception stems from the limited view of water as a revenue generating product. Advantages are overlooked due to the lack of systems thinking (OWCA 2011). In reality, reductions in non-revenue and revenue water result in significant savings in energy and chemical use, as well as longer term capital cost reductions. This represents a more sustainable plan, more resource efficient, and concerned with intergenerational and intragenerational equity.

Thus far, efforts to improve water use efficiency have focused largely on promoting the use of high efficiency, high performance water products and processes, through rebate programs, outreach and education in the value of conservation (ICF 2008). Reed (2012) highlights the importance of educating users as an important conservation tool, which also empowers the user, when information or technology is lacking. Strategies for water conservation invariably involve the consumer, whether utilities acknowledge it or not. A simple one-policy-fits-all approach is, therefore, unlikely to achieve meaningful results, since it neglects 
behavioral groupings and lifestyle types (Randolph and Troy 2008).

Another important aspect of most supply systems, besides the provision of water for everyday use, is the protection against fires. Water distribution systems are designed to serve consumers and to provide adequate flow for fire protection at all times. The rationale for this is that water not only has a large capacity for absorbing heat (and thus to bring cooling), but also the resulting steam when water is added to a fire stifles it by cutting off the supply of oxygen. Water is largely non-reactive and readily available, though water damage is undeniably a major price to pay for a structure saved from the fire. As distribution systems became increasingly large and complex in the last few centuries, water supply and provisions for firefighting have been added to their design criteria. Furthermore, in larger networks the provision of fire flow has a smaller effect on design, pressures in the system, and residence times.

In North America, the fire flow standard set by the Insurance Standards Office is widely applied and is used by insurance corporations to classify fire risks for municipalities. Fire flows and residual pressure requirements, however, vary significantly between countries, indicating obvious room for a safe decrease in energy use since this standard is currently much higher in North America than in other countries. One strategy that reduces fire liability, in addition to limiting the impact on system sizing, is the use of sprinkler systems. Utiskul and Wu (2011) estimate a reduction of $\geq 47 \%$ of the needed fire flow, and the projected water infrastructure demand for fire flow can be achieved in residential communities when homes are protected with fire sprinklers.

The planning of cities and their expansion should be a multi-objective decision making process, incorporating not only social, economic and environmental considerations, but also the different types of infrastructure which compose the urban environment. Population and economic growth inevitably increase water demand, and how such development occurs affects how much additional water, energy and costs are needed to maintain adequate delivery of water to all users.

USEPA (2006) presents four important connections between development patterns and water demand. First, large lots increase water demand, due to increased outdoor use, and require more length of pipe. Related to this is the second: low density housing increases leakage, demand and cost. Third, building new systems while deferring maintenance on older ones worsens water losses and costs. And last, development on and beyond the fringe can reduce the return on investment in infrastructure and raise costs. Integrating water and land use planning has, thus, undeniable advantages, yet is little practiced.

\section{Conclusions}

The proposed energy metrics integrate the two key parameters of the system, pressure and flow, and provide measures of water distribution sustainability. They can be used as indicators of system wide or local efficiency and susceptibility to bursts. Modeling facilitates the calculation of the metrics, especially for complex networks, with hourly variations, and allows for easy comparison of different scenarios, and alternatives for improvement. Mapping provides a geographical snapshot of network operation and enables reallocation studies since the cost (energy consuming) and revenue (water consuming) generating parts of the system are easily visualized.

In order to improve the systems, to make them more sustainable and less energy consuming, pressure and demand must be reduced. Obvious inefficiencies, such as aged pipes, leakage, and wasteful water use, are the usual targets. That does not mean, however, that there are not other opportunities for improvement, perhaps in practices ingrained in the system, standards that may have been taken for granted. Paradigms have shifted since water distribution systems were widely developed, almost a century ago. More is also known of the systems. Experience has been gained, and technology has enabled easy modeling and frequent data collection. All of which can inform more flexible, locally adapted designs.

\section{References}

AWWA (American Water Works Association). 2012. Buried No Longer: Confronting America's Water Infrastructure Challenge. Denver: AWWA.

Deb, A. K., F. M. Grablutz and Y. J. Hasit. 1995. Distribution System Performance Evaluation. Denver: American Water Works Association. ISBN 0898678226.

EPRI (Electric Power Research Institute). 2002. U.S. Electricity Consumption for Water Supply and Treatment: The Next Half Century. Vol. 4 of Water and Sustainability. Palo Alto: EPRI.

Gomes, R., A. S. Marques and J. Sousa. 2011. “Estimation of the Benefits Yielded by Pressure Management in Water Distribution Systems." Urban Water Journal 8 (7): 65-77.

Hussey, K. and J. Pittock. 2012. “The Energy-Water Nexus: Managing the Links between Energy and Water for a Sustainable Future." Ecology and Society 17 (1): 31.

ICF International. 2008. Water and Energy: Leveraging Voluntary Programs to Save Both Water and Energy. Washington, DC: U. S. Environmental Protection Agency.

Kumar, G. and B. W. Karney. 2012. "Natural Cities, Unnatural Energy?" Chap. 17 in The Natural City: Re-envisioning the Built Environment, edited by I. L. Stefanovic and S. B. Scharper. Toronto: University of Toronto Press. ISBN 9780802091604.

Lambert, A. O. 2000. “What Do We Know About Pressure-Leakage Relationships in Distribution Systems?" In Proceedings of the IWA Conference on System Approach to Leakage Control and Water Distribution Systems Management, Brno, Czech Republic. London: IWA. ISBN 80-7204-197-5.

Maas, C. 2010. Ontario's Water-Energy Nexus: Will We Find Ourselves in Hot Water ... or Tap into Opportunity? Victoria, 
B.C.: University of Victoria, Polis Project on Ecological Governance.

OWCA (Ontario Water Conservation Alliance). 2011. Being Water Smart: Conserving Water, Saving Money. Ottawa: OWCA.

Randolph, B. and P. Troy. 2008. "Attitudes to Conservation and Water Consumption." Environmental Science and Policy 2:441-55.

Reed L. K. 2012. “Capacity Building as a Policy Instrument in Water Conservation: A Case Study on Commercial, Industrial, and Institutional Consumers." Water Resources Management 26:3819-29.

Rossman, L. A. 2000. EPANET 2 Users' Manual. Cincinnati: USEPA National Risk Management Research Laboratory.

Rothausen, S. G. S. A. and D. Conway. 2011. “Greenhouse Gas Emissions from Energy Use in the Water Sector." Nature Climate Change 1:210-9.

Sahely, H. R. and C. A. Kennedy. 2007. “Water Use Model for Quantifying Environmental and Economic Sustainability Indicators." Journal of Water Resources Planning and Management 133 (6): 550-9.

Rebecca M. Dziedzic University of Toronto, Toronto, Ontario.

Bryan W. Karney University of Toronto, Toronto, Ontario.
Stokes, J. and A. Horvath. 2011. "Life-Cycle Assessment of Urban Water Provision: Tool and Case Study in California." Journal of Infrastructure Systems 17 (1): 15-24.

Tabesh, M., A. H. A. Yekta and R. Burrows. 2009. "An Integrated Model to Evaluate Losses in Water Distribution Systems." Water Resources Management 23:477-92.

The Nature Conservancy. 2011. More than Three-Quarters of Americans Don't Know Where Their Water Comes From. http:// www.nature.org/newsfeatures /pressreleases/more-thanthree-quarters-of-americans-dont-know-where-their-water-comes-from.xml.

Thornton, J. 2002. Water Loss Control Manual. New York: McGraw Hill. ISBN 0071374345.

USEPA (U. S. Environmental Protection Agency). 2006. Growing Toward More Efficient Water Use: Linking Development, Infrastructure, and Drinking Water Policies. Washington, DC: U. S. Environmental Protection Agency.

Utiskul, Y. and N. P. Wu. 2011. Residential Fire Sprinklers: Water Usage and Water Meter Performance Study. Quincy, MA: The Fire Protection Research Foundation. 